\title{
Combined Physiological and Anthropometrical Databases as Ergonomic Tools
}

\author{
Dieter Leyk $^{1), 2)}$, Gerd Küchmeister ${ }^{3)}$, Hans W. Jürgens ${ }^{3)}$ \\ 1) Central Institute of the Federal Armed Forces Medical Services, Koblenz, Department IV-Military Ergonomics \\ and Exercise Physiology, Germany \\ 2) German Sport University Cologne, Department of Physiology and Anatomy, Germany \\ 3) Research Group Physiological Anthropology, University of Kiel
}

\begin{abstract}
The purpose of this study was to establish an ergonomic basis for the integration of female personnel at military workplaces. The results of anthropometrical and physiological measurements of 1337 male and female subjects (aged 18-25 years) are presented. The empirical design included classical and functional body measures of high ergonomic relevance. Additionally, the isometric forearmflexor and knee-extensor forces of the subjects were tested as representative variables for their physiological suitability.

With regard to biometric and strength parameters, the present results clearly show only small overlaps between the sexes. Rating the 5th percentile of the male subjects as an exclusion value, the anthropometrical variables (sitting and standing body height measures, shoulder breadth, hand length and breadth etc.) show that $29 \%$ up to $72 \%$ of the women do not match this criterion. The situation becomes even worse when strength parameters are taken into consideration: Only $26 \%$ (knee extensors) respectively $3 \%$ (forearm flexors) of the females generate higher forces than the corresponding 5 th percentiles of their male counterparts.

The application of the database established in this survey aims at the integration of female personnel at all kinds of military workplaces; our data account for a combination of anthropometrical and physiological variables. In contrast to former systems based on isolated percentile tables, the results of our investigation make multivariate queries possible in optimization processes. This type of combined database is to be considered a useful tool for the evaluation of workplaces and personal equipment, for general ergonomic considerations and for personnel planning purposes to prevent applicants from occupational harm. J Physiol Anthropol 25(6): 363-369, 2006 http://www.jstage.jst.go.jp/browse/jpa2
\end{abstract}

[DOI: 10.2114/jpa2.25.363]

Keywords: anthropometrics, body measures, strength, integration of female personnel, military workplaces

\section{Introduction}

In industrial nations, physiological anthropologists have to focus on empirical investigations aiming at a high level of applicable results. They focus on topics such as safety and comfort at workplaces, and ergonomic product design. In this field, the adaptation of the technical environment according to the variability of human somatic characteristics is normally based on metric demands as recorded in detailed tables with body measures valid for national or international populations (Jüergens et al., 1998).

The importance of these investigations has increased considerably due to three undergoing processes: First, the sedentary lifestyle in conjunction with a hypercaloric diet has caused an increase in the number of obese and physically unfit adults, leading to considerable larger scatter of biometric and performance characteristics (Flegal et al., 1998; Leyk et al., 2005; WHO, 2000; Zimmet et al., 2001). Moreover, migration is regarded as responsible for an increase of the span of these variables in Germany. Lastly, there is a large increase in the number of women who are employed in traditionally maledominated occupations (Bhambhani and Maikala, 2000; Haward and Griffin, 2002). Taken together, these developments result in a larger spread of body measures, which is of paramount importance for personnel planning and the ergonomic optimization of workplaces.

However, in case of more compound purposes, the traditional type of database with single anthropometrical and physiological values which have been measured separately may have shortcomings. When individuals have to be assigned to highly specialised workplaces and the population is enlarged on short notice, a complex response is necessary. This is the case with the integration of female applicants for all kinds of military workplaces in the German army. In addition to genderrelated biometric differences, it has to be taken into account that manual lifting and carrying of loads are probably the most common types of exercise in everyday life in military service and that the absolute load to be encountered is often similar for 
both men and women (Bhambhani and Maikala, 2000; Leyk et al., 2006a, 2006b; Rice et al., 1996). Thus, strength measurements are also necessary for pre-employment screening and selection. In general, to evaluate the individual suitability on the one hand and the characteristics of the workplaces, personal equipment and man-machine interaction on the other, empirical designs with parallel raising of anthropometrical and physiological data have to be considered.

We can now present the results of such a combined investigation. The practical application of the results to be found in the combined database will allow occupational safety and comfort for all persons at military workplaces, men and women alike, and for optimization of their physical performance. Additionally, combined databases give reliable information concerning the amount of suitable applicants in a population. Further, they serve as a scientific background for establishing test and personnel planning procedures.

In this study a database was established by the combination of

- anthropometrical variables:

o classical body measures of high ergonomic relevance

o dynamic body measures (Erichsen et al., 1993)

- physiological variables:

o strength measures

$\circ$ vigilance and motor abilities

$\circ$ lifestyle factors (profession, physical training, nutrition)

The following description of methods and results focus on the classical body measure and strength variables of the investigation.

\section{Methods}

\section{Subjects}

- 1337 healthy army applicants

○1036 males

○ 301 females

- aged 18-25 years

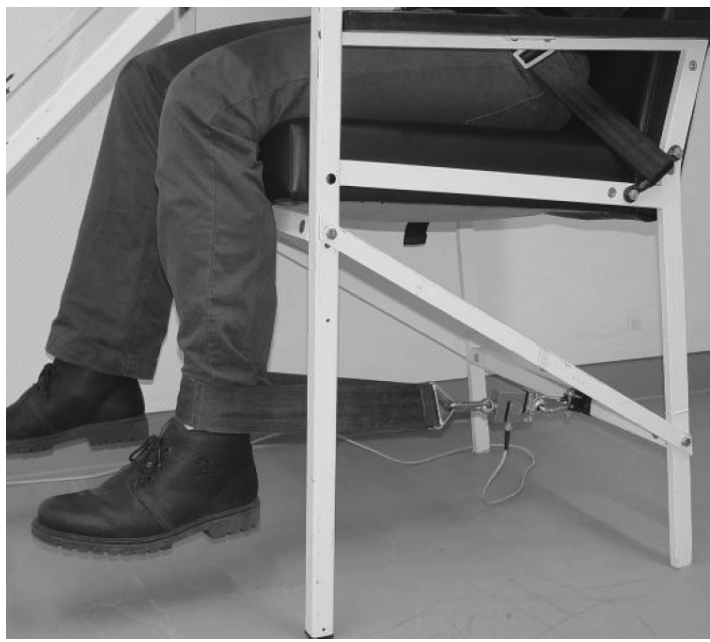

Fig. 1 Test position of the knee-extensor strength test. Subjects used their dominant leg.
- race component: $99.4 \%$ Europeans

\section{Classical body measures}

Definition and measuring method of the classical anthropometrical variables follow international standardization (ISO 7250). 23 body measures with a high ergonomic priority were taken from each subject, for example eye height sitting and standing, length of upper and lower extremities and circumferences for metric demands; hand and grip measures for the adaptation of physical man-machine interaction and face measures for designing different types of personal protective equipment.

Stature and body mass serve as key variables to estimate the constitutional type and to compare the actual results with values of other studies.

\section{Strength measures}

The subjects performed two strength tests with their dominant forearm flexors and knee extensors in sitting position. Using a force-measurement chair (Figs. 1 and 2) the volunteers were instructed to maintain maximal isometric force for $15 \mathrm{~s}$. Force-time profiles were measured by a strain gauge sensor (K-2565, Lorenz Messtechnik Ltd., Alfdorf, Germany; measuring range: $1500 \mathrm{~N}$, accuracy: $0.1 \%$ ) at a frequency of 50 $\mathrm{Hz}$. After correction of obvious outliers, the maximum value of all 750 data points was defined as maximum force $\left(F_{\max }\right)$.

Prior to strength measurements, volunteers were fixed with a seatbelt for accurate test position. The ankle of the dominant lower leg was connected to the strain gauge sensor by a wristband and an adjustable chain for knee-extensor strength measurements. The knee joint position was approximately $90^{\circ}$ (Fig. 1). Subjects performed the knee-extensor tests with arms crossed in front of their chest.

During the forearm-flexor-strength tests the upper arm was placed on a cushioned surface. The sitting volunteers were asked to grip a metal handle which was connected to the strain gauge sensor by an adjustable, but inelastic, wire cable (Fig.

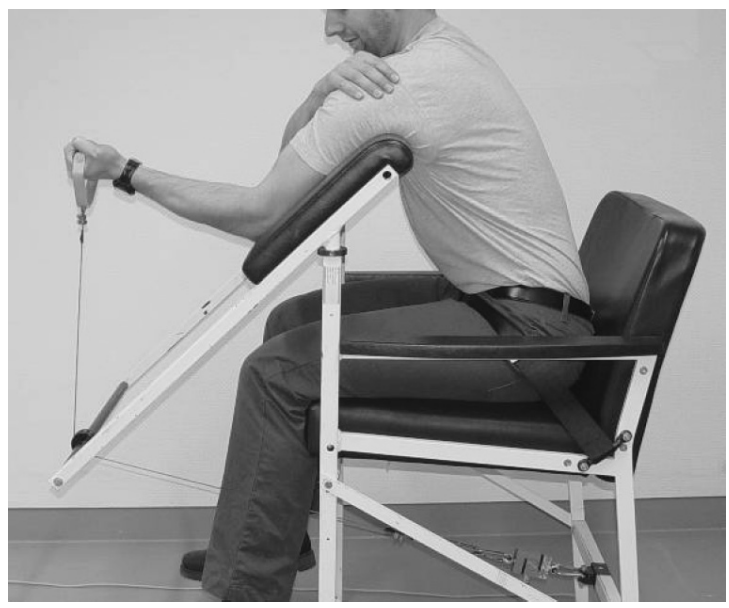

Fig. 2 Position of the forearm-flexor-strength test. Similar to the leg strength test, subjects used their dominant upper limb. 
Table 1 Percentile values of anthropometrical variables (P5, P50, P95 for females and males), population: healthy German army applicants, aged 18-25 years

\begin{tabular}{|c|c|c|c|c|c|c|}
\hline \multirow{3}{*}{ Body measures [mm] } & \multicolumn{3}{|c|}{ Females } & \multicolumn{3}{|c|}{ Males } \\
\hline & \multicolumn{6}{|c|}{ Percentiles } \\
\hline & P5 & P50 & P95 & P5 & P50 & P95 \\
\hline Stature & 1592 & 1674 & 1790 & 1690 & 1795 & 1914 \\
\hline Eye height standing & 1470 & 1557 & 1677 & 1567 & 1667 & 1796 \\
\hline Acromial height standing & 1305 & 1377 & 1487 & 1371 & 1472 & 1583 \\
\hline Shoulder-elbow length & 316 & 340 & 366 & 337 & 367 & 399 \\
\hline Forearm-hand length & 411 & 440 & 474 & 448 & 481 & 518 \\
\hline Bideltoid breadth & 393 & 430 & 472 & 435 & 473 & 523 \\
\hline Elbow-to-elbow breadth & 400 & 467 & 541 & 448 & 523 & 585 \\
\hline Hip breadth standing & 322 & 357 & 399 & 318 & 347 & 385 \\
\hline Foot length & 222 & 239 & 260 & 242 & 263 & 285 \\
\hline Chest circumference & 815 & 905 & 1031 & 870 & 955 & 1075 \\
\hline Waist circumference & 635 & 710 & 830 & 705 & 790 & 940 \\
\hline Buttock circumference & 879 & 980 & 1080 & 881 & 970 & 1090 \\
\hline Hand length & 164 & 176 & 190 & 177 & 191 & 205 \\
\hline Hand breadth & 71 & 77 & 83 & 79 & 86 & 93 \\
\hline Grip breadth interior & 44 & 50 & 54 & 48 & 54 & 60 \\
\hline Sitting height & 849 & 893 & 942 & 893 & 945 & 996 \\
\hline Eye height sitting & 732 & 776 & 823 & 772 & 825 & 881 \\
\hline Buttock-knee length & 536 & 577 & 627 & 563 & 607 & 657 \\
\hline Hip breadth sitting & 342 & 386 & 434 & 332 & 364 & 415 \\
\hline Knee height sitting & 468 & 502 & 550 & 496 & 543 & 592 \\
\hline Bizygomatic breadth & 115 & 125 & 134 & 117 & 129 & 143 \\
\hline Face length (menton-sellion) & 101 & 110 & 120 & 108 & 120 & 130 \\
\hline Body weight $[\mathrm{kg}]$ & 51.5 & 63.7 & 79.8 & 60.6 & 75.0 & 96.2 \\
\hline
\end{tabular}

2). In this test position the elbow joint of the test arm was approximately $120^{\circ}$. The hand of the other arm was positioned on the shoulder of the test side.

Before undergoing the strength tests, the subjects were familiarised with the test procedures and had at least one attempt to reach the maximum strength level. Maximal torque values $(\mathrm{Nm})$ were calculated by $F_{\max }(\mathrm{N}) \times$ lever arm $(\mathrm{m})$. Individual lever arms were measured prior to strength tests for both the lower leg (from the medio-lateral knee joint gap to the middle of the wristband) and the lower arm (from medial epicondyle to the middle of the handle).

\section{Results}

\section{Body measures}

In Table 1 the percentile values of the anthropometrical measures for male and female subjects are presented. Compared to the results of the national survey for the entire population (Jüergens 2004), male and female applicants for the army had higher values for stature and body mass. This tendency might be a consequence of self-exclusion by those who are aware of the physical demands of military workplaces, and their negative individual self-assessment before participating in the voluntary suitability test.

The integration-especially of smaller women-raises a
Table 2 Difference between 50th percentile male and female; exclusion rates for female subjects with regard to limitation by male percentiles

\begin{tabular}{lcc}
\hline $\begin{array}{c}\text { Anthropometrical key variables } \\
\text { of high ergonomic importance }\end{array}$ & $\begin{array}{c}\text { Difference } \\
\text { P50 male/P50 female }\end{array}$ & $\begin{array}{c}\text { Female subjects } \\
\text { values }<\text { P5 male }\end{array}$ \\
\hline Body measures & {$[\mathrm{mm}]$} & {$[\%]$} \\
Stature & 121 & 58 \\
Body height sitting & 52 & 49 \\
Shoulder breadth & 43 & 57 \\
Hand length & 15 & 53 \\
Hand breadth & 9 & 72 \\
Foot length & 24 & 58 \\
Shoulder height standing & 95 & 46 \\
Buttock-popliteal length sitting & 30 & 29 \\
Knee height (sitting) & 41 & 41 \\
Hip breadth (sitting) & -22 & $(13 \%$ above \\
& & P95 m) \\
Body mass & {$[\mathrm{kg}]$} & 36 \\
\hline
\end{tabular}

severe ergonomic problem, as shown by the values in Table 2 with relative data of anthropometrical key variables. Taking the 5th percentile for males (P5 male) as the limiting value (which is realistic for most of the traditional military workplaces and equipment details) a high percentage of female applicants have to be excluded for most body measures. Exclusion rates 
Table 3 Comparison of forearm-flexor-strength percentiles $\left(F_{\max }\right)$ of male and female subjects, virtually no overlapping of percentile spans (3\% of female subjects performed the test with higher values than P5 male)

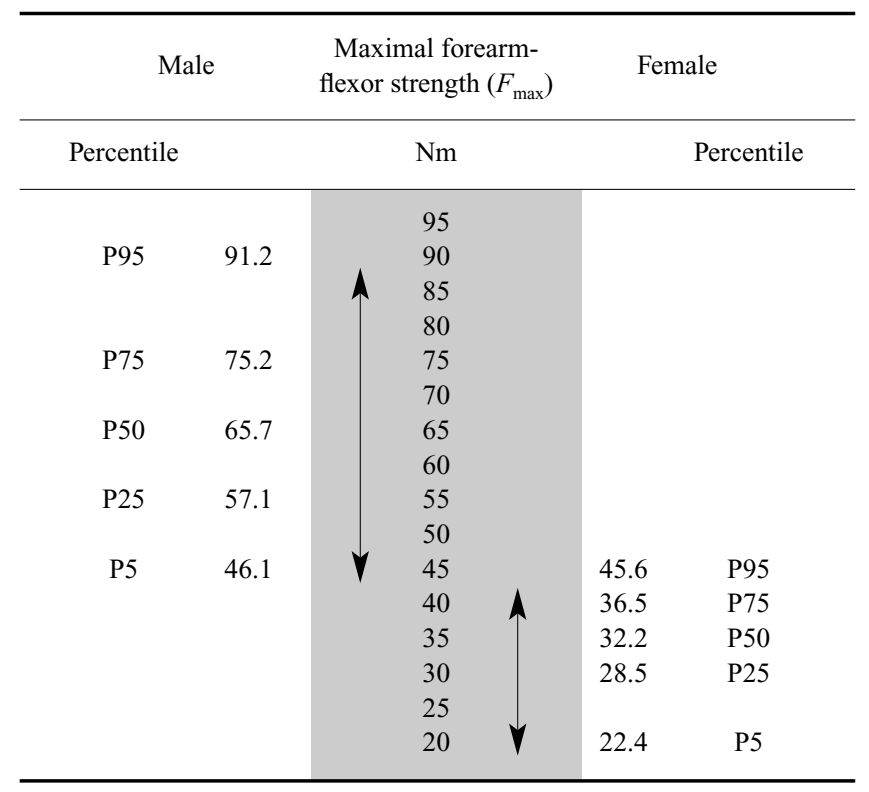

between $29 \%$ and $72 \%$ of the female applicants due to smaller body measures reveal that their integration will be a longer lasting and intensive ergonomic challenge. In a few cases, the body measures of female applicants are higher than male percentile values (e.g. hip breadth) due to sexual dimorphism. For practical applications, this will be relevant for re-scaling escape and revision openings.

Each ergonomic measure proposed to optimize the adaptation of military workplaces and equipment can now be accompanied by a multi-variable query of the database developed, and a cost-effect estimation is possible on short notice. But the integration of male and female applicants considering only metric aspects will not guarantee the safety necessary to avoid occupational harm. Each metric measure has to be additionally analysed by physiological queries, in this case by strength measures.

\section{Strength measures}

With regard to the maximal isometric force values $\left(F_{\max }\right)$ given in Tables 3 and 4 , the challenge for the integration of female personnel at military workplaces will increase. Accepting again the 5 th percentile of male forearm flexors a limiting value, the exclusion rate for female applicants is virtually $100 \%$, since the 5 th percentile male value of $46.1 \mathrm{Nm}$ corresponds to the 97 th percentile of female subjects (Table $3)$. The corresponding knee-extensor force values (Table 4) show that the overlap between men and women is certainly larger for the lower extremity. However, $74 \%$ of the females still produced less force than P5 male.
Table 4 Comparison of knee-extensor-strength percentiles $\left(F_{\max }\right)$ of male and female subjects, overlapping of percentile spans $(74 \%$ of female subjects performed the test with lower values than P5 male)

\begin{tabular}{|c|c|c|c|c|}
\hline \multicolumn{2}{|c|}{ Male } & $\begin{array}{l}\text { Maximal forearm- } \\
\text { strength }\left(F_{\max }\right)\end{array}$ & \multicolumn{2}{|c|}{ Female } \\
\hline Percentile & & $\mathrm{Nm}$ & & Percentile \\
\hline \multirow[t]{5}{*}{ P95 } & 284.7 & 280 & & \\
\hline & & 270 & & \\
\hline & & 260 & & \\
\hline & & 250 & & \\
\hline & & 240 & & \\
\hline \multirow[t]{3}{*}{ P75 } & 238.9 & 230 & & \\
\hline & & 220 & & \\
\hline & & 210 & & \\
\hline \multirow[t]{2}{*}{ P50 } & 207.3 & 200 & & \\
\hline & & 190 & & \\
\hline \multirow[t]{3}{*}{$\mathrm{P} 25$} & 181.0 & 180 & 186.8 & P95 \\
\hline & & 170 & & \\
\hline & & 160 & & \\
\hline \multirow[t]{7}{*}{ P5 } & 152.9 & 150 & 155.4 & P75 \\
\hline & & 140 & & \\
\hline & & 130 & 134.8 & P50 \\
\hline & & 120 & & \\
\hline & & 110 & 119.7 & P25 \\
\hline & & 100 & & \\
\hline & & 90 & 95.5 & P5 \\
\hline
\end{tabular}

\section{Discussion}

These data are not presented as a hypotheses-driven investigation. The goal of our study was to establish a database comprising anthropometrical and physiological parameters which can serve as useful tools for pre-employment screening, occupational prevention and the designing of personal equipment and workplaces. The present findings show that the sex-related differences in muscle strength and biometric measures are larger than previously reported (Laubach, 1976; Miller et al., 1993; Maughan, 1986; Jüergens, 2004) and that only small overlaps between young healthy men and women do in fact exist Leyk et al. 2006. This disparity to other studies is probably due to differences in the populations investigated: While our study focused on a rather homogeneous age group with a large number of young healthy subjects, other investigations comprised smaller samples covering up to sometimes 8 decades of age.

The results obtained for strength measures in addition to those for anthropometrical data indicate that the evaluation of workplaces and equipment, ergonomic optimization processes and personnel assignment on the base of strength percentiles can now be conducted in a very differentiated way. Even if metric problems actually do not occur at a workplace, the strength demands which take into consideration male and female percentile values may prevent ineffective personnel assignments. As an example, there is the manual stretcher transport which is an elementary task of ambulance and rescue 
services: The sustained hand-grip contraction and the eccentric strains during the transport require large hand-grip forces by ambulance personnel (Leyk et al., 2006a, 2006b; Rice et al., 1996; von Restorff, 2000). With regard to pre-employment screening, von Restorff (2000) proposed to consider only applicants whose hand-grip strength on the weaker side exceeds $334 \mathrm{~N}$.

A combined anthropometrical and physiological database can serve as a multi-functional tool to check the physical suitability for highly developed workplaces. Our findings based on the combination of anthropometrical and physiological parameters can serve the following purposes:

- practical application: individual check concerning the suitability of applicants according to body measures and strength

- practical application: evaluation of workplaces and manmachine interaction aiming at a step-by-step exclusion by ergonomic limits for body measures and force of prospective employees

- theoretical application: comparison of anthropological and physiological data of populations (historical and local

\section{differentiation)}

Scenario 1 for the application of the combined database: With the integration of female personnel into all kinds of military workplaces, the German army has to face a profound ergonomic challenge. Many of the workplaces and most of the equipment has been developed focussing on adaptation to male body measures.

Female applicants for a military workplace will accept only well defined limits in individual exclusion procedures. This exclusion cannot be defined by anthropometrical percentile values alone: For example, if the metric dimensions of a workplace would fit $50 \%$ of the female applicants with higher values in sitting height, even those have to be excluded if forearm forces higher than P5 male are required for manual tasks. For legal reasons and with respect to the high responsibility of the army as a public employer, these exclusion procedures have to be carried out for each military workplace and each equipment detail.

Scenario 2 for the application of the combined database: A complete re-organisation of military workplaces can be accompanied in the state of planning and construction. The

\begin{tabular}{|c|c|c|c|c|}
\hline \multicolumn{3}{|c|}{ Suitability determination } & \multirow{2}{*}{\multicolumn{2}{|c|}{ Total exclusion rate }} \\
\hline Step 1 & Step 2 & Step 3 & & \\
\hline Metric workplace profile & Anthropometrical matching & Exclusion rating & $\begin{array}{c}\text { Queries of isolated } \\
\text { databases }\end{array}$ & $\begin{array}{c}\text { Query of combined } \\
\text { databases }\end{array}$ \\
\hline Upper/lower metric limits & $\begin{array}{l}\text { Determination of } \\
\text { minimum/maximum male/ } \\
\text { female anthropometrical } \\
\text { value (Body measure) }\end{array}$ & $\begin{array}{l}\text { Exclusion rate } A^{*} \\
\text { (Applicants with } \\
\text { too low/high body } \\
\text { measure not suitable) }\end{array}$ & \multirow{3}{*}{$\mathrm{A}+\mathrm{P}$} & \multirow{3}{*}{$>(\mathrm{A}+\mathrm{P})$} \\
\hline Kinetic workplace profile & Physiological matching & Exclusion rating & & \\
\hline Minimum strength & $\begin{array}{c}\text { Determination of minimum } \\
\text { male/female physiological } \\
\text { value (Strength measure) }\end{array}$ & $\begin{array}{c}\text { Exclusion rate } p^{* *} \\
\text { (Applicants withlower } \\
\text { strength measure not suitable) }\end{array}$ & & \\
\hline \multicolumn{3}{|c|}{ Evaluation as a personnel managing tool } & Inadequate & Adequate \\
\hline
\end{tabular}

Fig. 3 Schematized comparison between methods: Suitability determination, computing total exclusion rate and evaluation of different database applications as personnel management tools $\left(* A\right.$ : by anthropometrical values, ${ }^{* *} p$ : by physiological values)

\begin{tabular}{|c|c|c|c|}
\hline \multirow{2}{*}{ Workplace profile } & \multicolumn{1}{c|}{$\begin{array}{c}\text { Technical construction or } \\
\text { optimization step (example) }\end{array}$} & \multicolumn{2}{|c|}{ Evaluation of prognosis about decrease of exclusion rates } \\
\cline { 2 - 4 } & $\begin{array}{c}\text { Expansion of work space, increase of } \\
\text { adjustment areas }\end{array}$ & Adequate \\
\hline Metric & $\begin{array}{c}\text { Decrease in operation strength of controls; } \\
\text { application of servo assistance }\end{array}$ & Adequate & Adequate \\
\hline Kinetic & Combination of steps above & Unsafe estimation & Directly linked quantification \\
\hline Metric/kinetic &
\end{tabular}

Fig. 4 Schematized evaluation of different database queries applied as tools in technical workplace construction or optimization 
consequence of each metric revision of a workplace or the construction of a product can be checked by queries of the combined database. For example, if the force which is necessary to use a special control or handle can be reduced in size and force, our database allows for the estimation of how many female applicants would be suited for it.

In both cases, satisfying solutions for the ergonomic challenges can be achieved by queries using the combined anthropometrical and physiological database to protect male and female applicants from occupational harm and the employer from faults in personnel planning processes.

The following Figs. 3 and 4 show the difference between isolated and combined databases regarding their function as tools for personnel management purposes (Fig. 3) and as tools for technical workplace construction and optimization processes (Fig. 4).

Applied as personnel management tools, databases have their main function in an adequate and safe determination of exclusion rates. The advantage of a database combining anthropometrical and physiological variables in this respect is obvious. The total exclusion rate computed by a query using the combined database exceeds the result of the queries of isolated databases and will provide safe and adequate evidence.

The direct linking of differentiated technical changes in a workplace (or a product, vehicle) with the amount of suitable persons which is featured by a database combining anthropometrical and physiological variables is the prerequisite for the advantages in the evaluation as an ergonomic tool. This is especially important in all those cases when combinations of optimization steps (concerning metric and kinetic measures) have to be evaluated with regard to their consequences for the rate of suitable persons.

Nevertheless, the structure of such a database can be enlarged by other variables, for example by further physiological variables concerning comfort (e.g. individual sweat rates, and mental and motor performance). The actual database is regarded as a first generation tool to be used in integrated physiological and anthropometrical personnel assignment and in a suitable workplace design.

\section{Conclusion}

In industrial nations, demographical, anthropometrical and physiological developments lead to a reduction of persons physically suited for complex occupational environments, such as military workplaces. Combined databases established by anthropometrical and physiological investigations are regarded as useful tools for occupational prevention and personnel planning measures. With respect to their multi-functional character in ergonomic evaluation processes, combined databases are milestones in the field of applied human sciences.

Acknowledgements This study was supported by the
Ministry of Defense, Federal Republic of Germany.

\section{References}

Bhambhani Y, Maikala R (2000) Gender differences during treadmill walking with graded loads: biomechanical and physiological comparisons. Eur J Appl Physiol 81: 75-83

Erichsen K, Jürgens HW (1993) Human Body Measures. Dynamic Body Measures. Report of the Federal Institute for Occupational Safety and Health Fb 670. Dortmund, Germany

Flegal KM, Carroll MD, Kuczmarski RJ, Johnson CL (1998) Overweight and obesity in the United States: prevalence and trends, 1960-1994. Int J Obes Relat Metab Disord 22: $39-47$

Haward BM, Griffin MJ (2002) Repeatability of grip strength and dexterity tests and the effects of age and gender. Int Arch Occup Environ Health 75: 111-119

Heyward VH, Johannes-Ellis SM, Romer JF (1986) Gender differences in strength. Res Q 57: 154-159

International Standards Organisation (ed.) ISO 7250 (1996) Basic human body measurements for technological design (ISO 7250: 1996)

International Standards Organisation (ed.) ISO 15535 (2003) General requirements for establishing anthropometrical databases (ISO 15535: 2003)

Jürgens HW (2004) Sampling of Anthropometrical data for the population group 40-65 year old persons. (Age group from 18-40 year old persons included in tables). Report of the Federal Institute for Occupational Safety and Health $\mathrm{Fb}$ 1023. Dortmund, Germany, 2004 (in German)

Jürgens HW, Matzdorff I, Windberg J (1998) International Anthropometrical Data for Work-Place and Machinery Design. Report of the Federal Institute for Occupational Safety and Health. Dortmund, Germany, 1998

Laubach, LL (1976) Comparative muscular strength of men and women: a review of the literature. Aviat Space Environ Med 47: 534-542

Leyk D, Rohde U, Gorges W, Ridder D, Wunderlich M, Dinklage C, Sievert A, Rüther T, Essfeld D (2005) Physical performance, body weight and BMI of young adults in Germany 2000-2004: Results of the Physical-Fitness-Test Study. Int J Sports Med 22: 642-647: DOI 10.1055/s2005-872907, published online

Leyk D, Rohde U, Erley O, Gorges W, Wunderlich M, Rüther T, Essfeld D (2006a) Recovery of hand grip strength and hand steadiness after exhausting manual stretcher carriage. Eur J Appl Physiol 96: 593-599: DOI 10.1007/s00421-005-0126-0, published online

Leyk D, Rohde U, Erley O, Gorges W, Essfeld D, Erren T, Piekarski C (2006b) Maximal manual stretcher carriage: Performance and recovery of male and female ambulance workers. Ergonomics (in press)

Leyk D, Gorges W, Ridder D, Wunderlich M, Rüther T, Sievert A, Essfeld D (2006c) Hand-grip forces of young men, 
women and highly trained female athletes. Eur J Appl Physiol (in press)

Maughan RJ, Harmon M, Leiper JB, Sale D, Delman A (1986) Endurance capacity of untrained males and females in isometric and dynamic muscular contractions. Eur J Appl Physiol 55: 395-400

Miller AEJJD. MacDougall, Tarnopolsky MA, Sale DG (1993) Gender differences in strength and muscle fiber characteristics. Eur J Appl Physiol 66: 254-262

Rice VJB, Tharion WJ, Sharp MA, Williamson TL (1996) The effects of gender, team size, and a shoulder harness on a prolonged stretcher-carry task and post carry performance. Part I. A simulated carry from a remote site. Int J Ind Ergon 18: $27-40$

Restorff von W (2000) Physical fitness of young women: Carrying simulated patients. Ergonomics 43: 728-743
World Health Organisation (ed.) (2000) Obesity. Preventing and managing the global epidemic. In: Report of a WHO Consultation; i-xii: 1-253

Zimmet P, Alberti KGMM, Shaw J (2001) Global and societal implications of the diabetes epidemic. Nature 414: 782-787

Received: March 2, 2006

Accepted: September 22, 2006

Correspondence to: Dieter Leyk, Central Institute of the Federal Armed Forces Medical Services Koblenz, Department IV-Military Ergonomics and Exercise Physiology, Andernacher Str. 100, 56070 Koblenz, Germany

Phone: +492618967400

Fax: +492618967109

e-mail: Leyk@dshs-koeln.de 